\title{
The Inability of Neisseria gonorrhoeae Pili Antibodies to Confer Immunity in Subcutaneous Guinea-pig Chambers
}

\author{
By W. H. TURNER AND P. NOVOTNY \\ Department of Bacteriology, Wellcome Research Laboratories, \\ Beckenham BR3 3BS, Kent
}

(Received 17 July 1975; revised 5 September 1975)

\section{INTRODUCTION}

Tests with subcutaneous chambers in guinea pigs (Arko, 1972) showed that virulent strains of Neisseria gonorrhoeae survive therein for several weeks. Avirulent strains, on the other hand, are either unable to infect the chamber or are eliminated after a few days. Using this model, Arko (1974) successfully prevented infection of such chambers by virulent strains either by active immunization with a formolized vaccine or passively by administration of serum from an immunized animal. Spontaneous immunity was also observed, reinfection being unsuccessful when established infection of the chamber had died out. The protection afforded was highly specific, being exhibited against the homologous strain only. Since similar strain-specific protection was also observed in chimpanzees (Arko et al. 1974) the guinea-pig model was considered appropriate to the study of immunity to $N$. gonorrhoeae. Indeed this model has been used successfully by several workers (Scales \& Kraus, 1974; Veale et al. 1975).

Immune electron microscopy using rabbit antisera showed that pili of different strains of $N$. gonorrhoeae are antigenically heterogeneous with cross-reactions occurring only rarely (Novotny \& Turner, 1975). It was of interest to know whether serological cross-reaction in pili would reflect cross-protection in the guinea-pig model. If correlation between the serological behaviour of pili and protection exists, the specificity of pili antibodies could be used for the screening of strains suitable for vaccines. This enquiry formed the basis of this study.

\section{METHODS}

Culture media. These were GC agar (Difco) plates with supplements (Kellogg et al. 1963), and liquid GC medium as used previously (Novotny \& Turner, 1975).

Organisms. Neisseria gonorrhoeae stG2, stG4, stG6, stG1 8 and stG38 of Novotny \& Turner (1975) were used. The strains were kept as frozen suspensions in a liquid nitrogen container (LD 40, Union Carbide). Cells from GC plates were suspended in $0.05 \mathrm{M}$-tris- $\mathrm{HCl}$ buffer pH $7 \cdot 6$, containing $(\mu \mathrm{mol} / \mathrm{ml})$ : monosodium L-glutamate, 57 ; L-proline, 2 ; and glycerol, $\mathrm{IO}^{5}$. All strains used were found to be sufficiently virulent for guinea-pig chambers.

Examination of pili. The serological examination of pili was carried out as described (Novotny \& Turner, 1975), using either rabbit antisera or sera from vaccinated or infected guinea pigs.

Rabbit antisera reacted as follows: stg4 antiserum reacted with the pili of both the homologous strain and those of StG 38 and StG 8 . StG 38 antiserum reacted with the pili of the homologous strain and with those of StG2, stg4 and stgI8. Sera against stg2 and stG6 reacted with homologous pili only. Although the stock cultures of the strains studied were 
kept with the lowest possible number of passages, neither selective subculture on GC plates nor 'storage' for 2 to 5 months in the guinea-pig chambers affected the serological behaviour of the pili.

The pili referred to in this paper are, according to Novotny, Short \& Walker (1975), the most common gonococcal pili, namely type $a$ pili. Pili with a knob at one end (pili $c$ ), which may be sex pili, have not been specifically distinguished in this paper.

Guinea-pig chambers. Chambers were made from $2 \mathrm{ml}$ polypropylene ampoules (Sterilin, No. 506) by sealing the open ends in the heated end of a test tube and then cutting 12 to 15 holes $(2 \times 4 \mathrm{~mm})$ in the ampoule with a grinding wheel.

Implantation of chambers. Following anaesthesia with sodium pentobarbitone (Nembutal veterinary - Abbott; $0.13 \mathrm{ml} / \mathrm{I00} \mathrm{g}$ body wt, intraperitoneally), shaving and disinfection of the skin $(5 \%, w / v$, iodine in $70 \%$ ethanol containing $10 \%, w / v$, potassium iodide), two paramedian ventral incisions were made in the skin. Through each incision two chambers were implanted, wide apart, beneath the skin, which was then sutured with surgical braided nylon. Finally the sutured incisions were dressed with Nobecutane Spray (BDH). Usually, each guinea pig had four well-separated chambers. Post-operative infection occurred in about $5 \%$ of the chambers implanted; these were removed.

Immunization and challenge. Guinea pigs (Charles River: Duncan Hartley, 500 to $700 \mathrm{~g}$ ) were immunized with whole cell preparations of gonococci which had been washed off GC plates with saline $(0.85 \%, \mathrm{w} / \mathrm{v}, \mathrm{NaCl})$ after $18 \mathrm{~h}$ incubation at $37^{\circ} \mathrm{C}$ in a $\mathrm{CO}_{2}$ incubator. The gonococci were suspended in I \% (v/v) formol-saline for $24 \mathrm{~h}$ at $4^{\circ} \mathrm{C}$, washed with saline by centrifugation at $2000 \mathrm{~g}$ for $15 \mathrm{~min}$ at $4^{\circ} \mathrm{C}$, and finally resuspended in saline to a cell density equivalent to $1 \cdot 0 \times 10^{8}$ to $2.0 \times 10^{8}$ c.f.u. $/ \mathrm{ml}$ and $\mathrm{I} \mathrm{mg} \mathrm{AlPO} / \mathrm{ml}$. A vaccine of stG 38 was also prepared from a culture grown in GC liquid medium in shake flasks. After $20 \mathrm{~h}$ incubation at $37^{\circ} \mathrm{C}$ the culture was formolized and processed in the same way as those grown on GC plates. This vaccine is designated stG38 liquid.

The guinea pigs were immunized subcutaneously with two $1.0 \mathrm{ml}$ doses of the antigen preparations given at intervals of 1 month. Implantation of the chambers was done 7 to 8 days after the first injection of antigen and each one was checked for sterility before the animals were challenged. The chambers were challenged with approximately $10^{7}$ c.f.u. I I days after the second injection. This dose consistently infected the control chambers.

Assessment of protection. Guinea pigs were immunized in groups of seven with five different vaccine preparations. Each of the chambers was challenged with a different strain and 0.1 to $0.2 \mathrm{ml}$ samples of exudate were taken 3 and 7 days after challenge. One drop of the sample was spread over a GC plate. If any gonococcal colonies could be detected on the plates after $24 \mathrm{~h}$ incubation the guinea pig was recorded as unprotected. In most unprotected guinea pigs both the 3 and the 7-day samples were positive. Occasionally one of the samples was positive, in which case the guinea pig was recorded as unprotected. In positive cultures, results varied between confluent growth and the formation of a number of isolated colonies on the plate; exceptionally, only one or two colonies were detected.

\section{RESULTS AND DISCUSSION}

In most cases it was not possible to establish infection in chambers in immunized guinea pigs when these were challenged with the homologous strain (Table I). However, there were

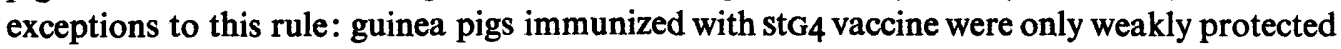
against homologous challenge ( 5 out of 7 chambers being infected), and StG 8 vaccine was ineffective in these tests. Guinea pigs immunized with stG4 vaccine were immune to challenge 
Table I. Efficacy of N. gonorrhoeae vaccines as tested in a guinea-pig model. challenged with homologous and heterologous strains

\begin{tabular}{|c|c|c|c|}
\hline $\begin{array}{c}\text { Strain used } \\
\text { for vaccination }\end{array}$ & $\begin{array}{l}\text { Strain used for } \\
\text { challenge }\end{array}$ & $\begin{array}{l}\text { No. of infected } \\
\text { chambers/ } \\
\text { total no. } \\
\text { of chambers }\end{array}$ & $\begin{array}{l}\text { Serological cross- } \\
\text { reactivity of } \\
\text { challenge strain } \\
\text { pili with rabbit } \\
\text { antiserum against } \\
\text { vaccine strain }\end{array}$ \\
\hline stG4 & $\begin{array}{l}\text { StG2 } \\
\text { stG4 } \\
\text { stG6 } \\
\text { stG } 8 \\
\text { stG38 }\end{array}$ & $\begin{array}{l}3 / 3 \\
5 / 7 \\
0 / 4 \\
4 / 4 \\
4 / 4\end{array}$ & $\begin{array}{l}- \\
+ \\
+ \\
+ \\
+\end{array}$ \\
\hline stG6 & $\begin{array}{l}\text { stG2 } \\
\text { stG4 } \\
\text { stG6 } \\
\text { stG I } 8 \\
\text { stG38 }\end{array}$ & $\begin{array}{l}4 / 4 \\
3 / 3 \\
0 / 4 \\
3 / 4 \\
3 / 3\end{array}$ & $\begin{array}{l}- \\
- \\
+ \\
-\end{array}$ \\
\hline stg I 8 & $\begin{array}{l}\text { stG2 } \\
\text { stG4 } \\
\text { stG6 } \\
\text { stG I } 8 \\
\text { stG38 }\end{array}$ & $\left.\begin{array}{l}3 / 4 \\
3 / 4 \\
3 / 4 \\
3 / 4 \\
3 / 3\end{array}\right\}$ & $\begin{array}{l}\text { Rabbit serum } \\
\text { against } \\
\text { stG18 not } \\
\text { raised }\end{array}$ \\
\hline stg38 & $\begin{array}{l}\text { stG2 } \\
\text { stG4 } \\
\text { stG6 } \\
\text { stG18 } \\
\text { stG38 }\end{array}$ & $\begin{array}{l}3 / 3 \\
3 / 3 \\
3 / 3 \\
3 / 3 \\
0 / 3\end{array}$ & $\begin{array}{l}+ \\
+ \\
- \\
+ \\
+\end{array}$ \\
\hline stG38 liquid & $\begin{array}{l}\text { stG2 } \\
\text { stG4 } \\
\text { stG6 } \\
\text { stG I } 8 \\
\text { stG38 }\end{array}$ & $\begin{array}{l}4 / 4 \\
3 / 3 \\
3 / 4 \\
3 / 3 \\
0 / 4\end{array}$ & $\begin{array}{l}+ \\
+ \\
- \\
+ \\
+\end{array}$ \\
\hline $\begin{array}{l}\text { Unimmunized } \\
\text { controls }\end{array}$ & $\begin{array}{l}\text { stg2 } \\
\text { stG4 } \\
\text { stg6 } \\
\text { stG I } 8 \\
\text { stg38 }\end{array}$ & $\left.\begin{array}{l}4 / 4 \\
3 / 3 \\
4 / 4 \\
3 / 3 \\
2 / 2\end{array}\right\}$ & $\begin{array}{c}\text { Not } \\
\text { applicable }\end{array}$ \\
\hline
\end{tabular}

with stG6 even though stG6 pili did not cross-react with hyperimmune rabbit serum raised against StG4 pili and stG4 pili did not react with stG6 antiserum. This was the only case of cross-protection observed and confirms the conclusion of Arko (1974) that a complete cross-protection against different strains cannot normally be achieved in the guinea-pig model. In no case where pili cross-reacted with heterologous antiserum was cross-protection conferred. For example, guinea pigs immunized with $\mathrm{stg}_{3} 8$ vaccine were not protected against challenge with StG2, StG4 and StGI 8 even though pili from all these strains crossreacted with StG38 antiserum. We thus conclude that there is no correlation between crossprotection and the serological cross-reactivity of pili from different strains as detected by immune electron microscopy.

In general, all the vaccines used appeared to be of low potency since relatively high doses were necessary to protect the chambers. Vaccine StG38 prepared from a liquid culture was as potent as one prepared from cells grown on GC plates.

In unimmunized control groups of guinea pigs the infection persisted for 2 months in 
9 of 24 chambers, and less often for 3 to 4 months. In one case the infection persisted for more than 5 months. Few strains were eliminated within 6 weeks and some, not suitable for this type of experiment, were unable to infect the chamber at all although the inoculum consisted of TI and T2 colonies (Kellogg et al. 1963) and contained pili.

When the chamber contents of control guinea pigs were found to be free of infection in two consecutive samples taken a week apart, the chambers were reinfected with homologous or heterologous strains. No case of cross-protection was found although the guinea pigs were usually protected against homologous strain challenge either completely (as with StG38) or partially (as with StG4, where $I$ in 4 chambers tested was reinfected). As with StG 8 immunization, previous infection with this strain conferred no protection.

Control guinea pigs originally infected with four different strains may be immune against all four strains on rechallenge, whether the reinfection is applied to the same chamber or a completely different one. There is therefore no evidence of localized immunity in the chambers.

Guinea pigs initially infected with stG4 were found to be better protected by previous infection than by vaccination ( 5 out of 7 infected after vaccination; 1 out of 4 infected after previous infection). Although vaccination with stG4 vaccine conferred immunity against stG6 (Table I), previous infection with stG4 did not protect against stG6. This suggests that several different factors may be involved in immunity. Certainly it appears that the factor(s) responsible for the virulence of strains in guinea-pig chambers has no direct relationship to their protective properties. This is illustrated by StGI8 which was unable to protect against infection of the chamber either in the form of a vaccine or by 'natural' infection lasting for 2 to 3 months.

Antipili antibodies were detected by immune electron microscopy in both the sera of guinea pigs which had been immunized and in control guinea pigs in which the infection had died out. When the sera were diluted only 5 to 10 times in the normal reaction mixture the whole surfaces of the pili were coated with IgG. Sera had to be diluted approximately 400 -fold before individual antibodies were observed. This was found to be the case even with the guinea pigs immunized or infected with strain StGI8, which remained unprotected against homologous challenge in these experiments. Such animals, although able to 'neutralize' the pili surface, were not immune to reinfection of the chambers with stGi 8 .

The immunity achieved either by vaccination or through 'natural' infection, therefore, does not depend on the formation of pili antibodies. Doubts have already been cast upon the role of pili in human gonorrhoea. Under natural conditions in pus, pilated cocci are relatively rare compared with the number of cells without pili (Novotny et al. 1975), yet this has apparently little influence on the attachment of gonococci to human leucocytes (Swanson et al. 1974). Also, pilation of gonoccoci has little effect, if any, on the activity of phagocytes (Swanson, King \& Zeligs, 1975).

Although homologous protection in the guinea-pig model correlated with the results on chimpanzees (Arko et al. 1974), it is not certain whether the guinea-pig model is a relevant model for the immunity of human gonococcal infection. Nevertheless, the lack of immunity in guinea-pig chambers to the heterologous challenge seems to parallel the apparent lack of immunity to reinfection with gonococci in clinical experience in man. If a high diversity of immunotypes of $N$. gonorrhoeae is the explanation, the model may be valid; thorough comparative investigations are necessary to ensure the validity of the test.

In view of these considerations and the results presented in this paper, the likelihood of making a vaccine for gonorrhoea by raising high titres of antipili antibodies does not seem to be great. 
We are grateful to Miss Carol Briselden for excellent technical assistance in this study. We thank Mr J. A. Short, Miss Christine Syrett and Mr P. Rowden for their assistance in the electron microscopy.

\section{REFERENCES}

ARKo, R. J. (1972). Neisseria gonorrhoeae: experimental infection of laboratory animals. Science, New York I77, 1200-1201.

ARko, R. J. (1974). An immunologic model in laboratory animals for the study of Neisseria gonorrhoeae. Journal of Infectious Diseases 129, 45I-455

Arko, R. J., Kraus, S. J., Brown, W. J., Buchanan, T. M. \& Kuhn, U. S. G. (1974). Neisseria gonorrhoeae: effect of systemic immunization on resistance of chimpanzees to urethral infection. Journal of Infectious Diseases r30, 160-164.

Kellogg, D. S., Peacock, W. L., Jun. Deacon, W. E., Brown, L. \& Pirkle, C. I. (I963). Neisseria gonorrhoeae. I. Virulence genetically linked to clonal variation. Journal of Bacteriology 85, I274-1 279.

Novotny, P., ShORT, J. A. \& WALKeR, P. D. (1975). An electron microscope study of naturally occurring and cultured cells of Neisseria gonorrhoeae. Journal of Medical Microbiology 8, 413-427.

NovotnY, P. \& TURNER, W. H. (1975). Immunological heterogeneity of pili of Neisseria gonorrhoeae. Journal of General Microbiology 89, 87-92.

Scales, R. W. \& Kraus, S. J. (I974). Development of passive transfer of immunity to gonococcal infection in guinea pigs. Infection and Immunity 10, 1040-1043.

Swanson, J., KING, G. \& Zeligs, B. (1975). Studies on gonococcus infection. VII. In vitro killing of gonococci by human leukocytes. Infection and Immunity II, 65-68.

Swanson, J., Sparks, E., Zeligs, B., Siam, M. A. \& Parrott, C. (1974). Studies on gonococcus infection. V. Observation on in vitro interactions of gonococci and human neutrophils. Infection and Immunity ro, 633-644.

Veale, D. R., Smith, H., Wirt, K. A. \& Marshall, R. B. (1975). Differential ability of colonial types of Neisseria gonorrhoeae to produce infection and an inflammatory response in subcutaneous perforated plastic chambers in guinea-pigs and rabbits. Journal of Medical Microbiology 8, 325-335. 